\title{
Nurse-Doctor Co-Teaching: A Pilot Study of the Design, Development, and Implementation of Structured Interprofessional Co-Teaching Sessions
}

This article was published in the following Dove Press journal: Advances in Medical Education and Practice

\author{
Marina E Zambrotta $\mathbb{D}^{1,2}$ \\ Patricia Aylward ${ }^{3}$ \\ Christopher L Roy ${ }^{1,2}$ \\ Emily Piper-Vallillo ${ }^{1,4}$ \\ Stephen R Pelletier ${ }^{2}$ \\ James P Honan ${ }^{4}$ \\ Noah Heller ${ }^{4}$ \\ Subha Ramani ${ }^{1,2}$ \\ Helen M Shields $\mathbb{D}^{1,2}$ \\ 'Department of Medicine, Brigham and \\ Women's Hospital, Boston, MA, USA; \\ ${ }^{2}$ Harvard Medical School, Boston, MA, \\ USA; ${ }^{3}$ Department of Nursing, Brigham \\ and Women's Hospital, Boston, MA, \\ USA; ${ }^{4}$ Harvard Graduate School of \\ Education, Cambridge, MA, USA
}

Introduction: High levels of interprofessional collaboration are beneficial for patients and healthcare providers. Co-teaching may be one method for creating a collaborative environment. This pilot study designed, developed, and implemented Nurse-Doctor Co-Teaching on an inpatient medicine service.

Methods: Ten Nurse-Doctor Co-Teaching pairs designed 30-minute, structured co-teaching sessions with learning objectives, evidence-based content, interactive teaching strategies and a Take-Away of key content with the help of a coaching team. Each session was presented by a nurse and senior doctor to nurse and resident learners. Our assessment blueprint included: 1. Anonymous surveys assessing the overall rating of each session and 2. Pre- and postanonymous surveys assessing measures of interprofessional collaboration and communication between nurses and residents before and after the series of ten co-teaching sessions.

Results: Data from ten post-session surveys included 121 of 156 participants $(77.6 \%)$. Attendance at each session ranged from 13-19 participants with 8-17 participants completing a survey per session for an average of 12.1 surveys analyzed. All Nurse-Doctor CoTeaching sessions scored in the excellent range between 1.00 and 1.43 on a Likert scale ( 1 is excellent and 5 is poor). In response to the question "What did you like best?", interactive teaching strategies was the most frequent spontaneous answer. A significant correlation between the number of interactive teaching strategies and enjoyability of the session ( $p$-value $=0.01$ ) was observed. Measures of interprofessional collaboration and communication did not change significantly in the pre-intervention compared to post-intervention period. Conclusion: We created a unique model of interprofessional co-teaching on an inpatient service. The overall excellent ratings of our interactive sessions indicate that Nurse-Doctor Co-Teaching is a valued form of learning. Our structured format is adaptable to various medical settings and could be expanded to include additional allied health professionals. We plan further studies to assess if Nurse-Doctor Co-Teaching improves measures of interprofessional collaboration.

Keywords: interprofessional co-teaching, interactive teaching strategies, nursing education, resident education, coaching team, faculty development

\section{Introduction}

Interprofessional education plays a critical role in our healthcare system. ${ }^{1}$ High levels of interprofessional collaboration and communication have been shown to lead to better patient outcomes, improved patients' satisfaction, as well as higher job satisfaction for nurses and doctors. ${ }^{2-5}$ A controlled trial of structured interdisciplinary rounds on a medical teaching unit has been shown to improve measures of nurse
Helen M Shields

Department of Medicine, Brigham and Women's Hospital, 75 Francis Street,

Boston, MA, 02115, USA

Tel +I 40I-499-3874; + I 617-678-6077

Fax + 1 918-233-2180; +1617-525-8740

Email Mzambrotta@partners.org;

Hmshields@bwh.harvard.edu
Advances in Medical Education and Practice 2021:12 339-348

bmit your manuscrip in $\square$ 
collaboration. ${ }^{6}$ Collaboration is a shared partnership that involves cooperation, communication, trust, respect, and understanding. 6,7

Nurses and doctors encounter barriers to collaboration, such as the historical hierarchy that exists in the medical setting, as well as a misunderstanding of each other's roles, knowledge, and responsibilities. ${ }^{2,8,9}$ We recognized the utility of opportunities that involve nurses and doctors equally and actively, not only in clinical care, but also in co-teaching and learning together.

Co-teaching involves two professionals jointly delivering substantive instruction to a group of learners in a single physical space. ${ }^{10}$ A co-teaching partnership is based on the spirit of equality, shared goals, and accountability. ${ }^{10-12}$ Co-teaching was originally developed in the general education setting. However, studies have shown that it can lead to productive educational experiences when adapted to medical education. ${ }^{10-12}$

Prior studies on resident preferences for learning have demonstrated the importance of incorporating principles of adult learning theory and active learning, as well as making a commitment to faculty development. ${ }^{13-16}$ Additionally, residents infrequently mention nurses and other allied health professionals as participants in their useful learning experiences. $^{17}$ Our aim was to utilize available literature about resident learning preferences, apply these to a structured interprofessional co-teaching model, and evaluate our intervention for 1 . Overall teaching effectiveness and 2. Measures of nurse-doctor collaboration.

\section{Methods}

\section{Recruitment of Nurses and Doctors as Co-Teachers}

A "Kickoff Dinner" was held two weeks before the first Nurse-Doctor Co-Teaching session to introduce the concept of co-teaching. The program consisted of: 1 . Interactive co-teaching of "The French Lesson" (Harvard Business School Publishing, Case No. 9-384-066 by Abby Hansen) by experienced co-teachers from the Harvard Graduate School of Education (JH, NH). ${ }^{18}$ 2. An example of a Nurse-Doctor Co-Teaching session led by a nurse and a doctor (PA, MZ). 3. Question and answer session.

\section{Selection and Pairing of Nurse-Doctor Co-Teacher Pairs}

After recruiting ten nurses and ten doctors, they were randomly assigned into co-teaching pairs based on availability.
If more than one nurse and one doctor matched to a particular date, a random number generator was used by our statistician (SP) to select a number corresponding to a specific nurse and doctor.

\section{Faculty Development and Coaching Team Sessions}

Here, "doctor" refers to a senior internal medicine physician who was paired with a nurse to co-teach a session. "Resident" refers to the internal medicine resident physicians who were included as learners in this study and were taught, alongside nurses, by a co-teaching pair. We used the term co-teaching in the sense of "team teaching" and the "co-teaching pair" refers to the team of one nurse and one doctor who co-teach a session. ${ }^{10,12}$ The "coaching team" refers to a group of two doctors (MZ, HS) and one educational specialist (EPV) who mentored the coteaching pairs.

Each co-teaching pair met with the coaching team for a series of planning sessions. The number of planning sessions varied among each pair of co-teachers, but ranged from three to six sessions, each lasting from 20 to 60 minutes. At the first session, the co-teaching pair chose a topic that was interesting and relevant to both the coteachers and the co-learners. At the second session, the pair decided on learning objectives and chose interactive teaching strategies to teach the topic from multiple angles, frequently with a modified team-based learning approach. ${ }^{19-22}$ A Take-Away, a one-page summary of high yield learning points, was prepared by the coaching team and reviewed by the co-teaching pair. ${ }^{19,23,24}$ At the third session, the coteachers taught their session as a dress rehearsal, with direct observation and feedback from the coaching team (MZ, HS, EPV).

\section{Blueprint for Assessment}

Our blueprint for assessment (Figure 1) included: 1. Anonymous surveys evaluating each of the ten co-teaching sessions for its overall rating as well as enjoyability and effectiveness as a teaching method and 2. Pre-and postintervention anonymous daily surveys of nurses (Supplementary Appendix 1) and residents (Supplementary Appendix 2) on the general medicine service for a nine-day "run-in" pre-intervention period and daily anonymous surveys of nurses and residents for a nine day "run-out" postintervention period. Each nurse or resident filled out the survey only once throughout these time periods. While the 


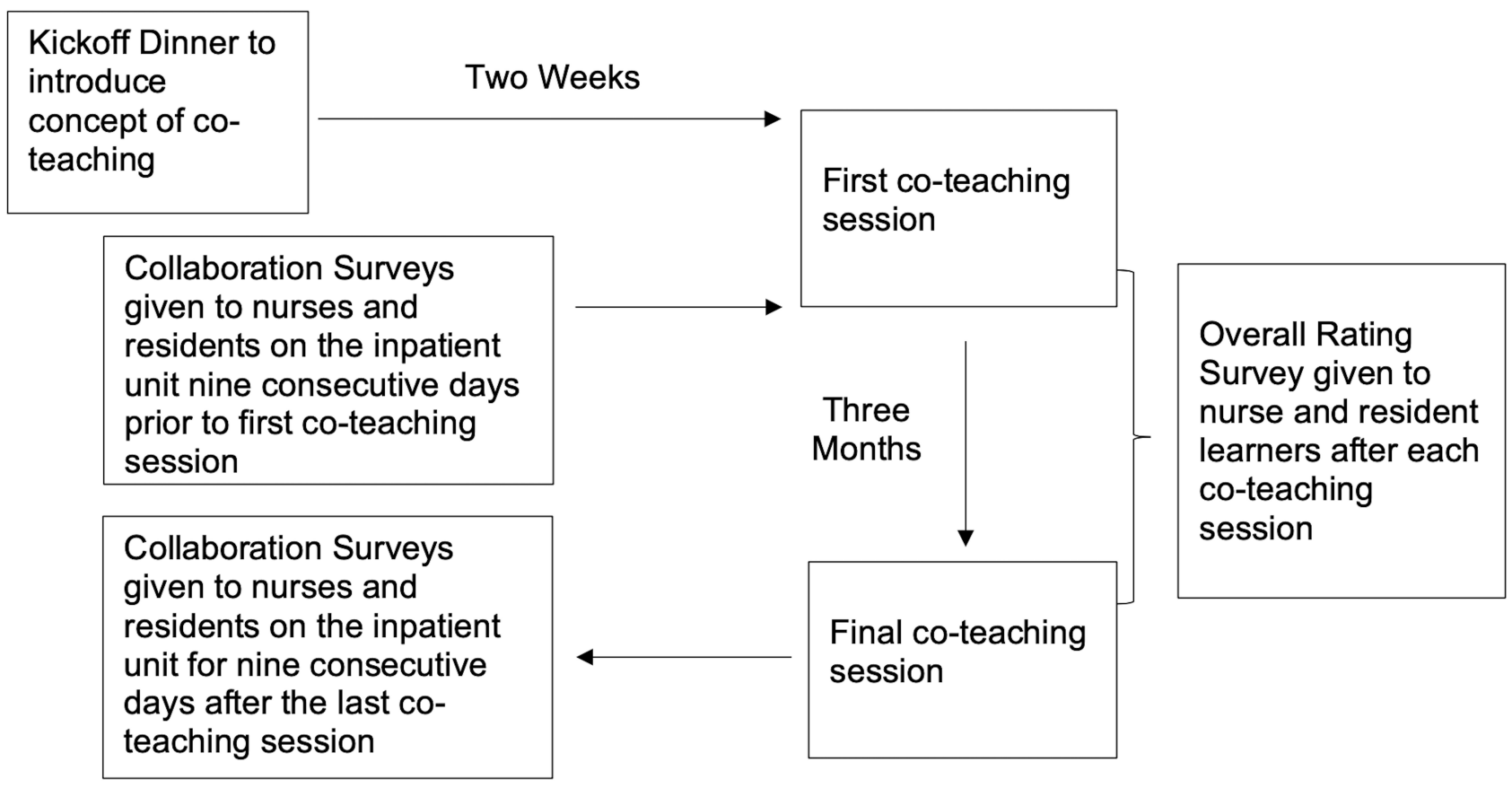

Figure I Blueprint for assessment of Nurse-Doctor Co-Teaching sessions. Timeline highlighting the two-week interval between the Kickoff Dinner and first co-teaching session and the three-month interval between the pre- and post- Collaboration Surveys given to nurses and residents. Each of the ten Nurse-Doctor Co-Teaching sessions was evaluated by an overall rating survey.

majority of the nurses surveyed were the same nurses in the pre- and post-intervention period, the residents were not. Residents changed every two weeks over the three-month period as this is the institutional structure of this general medicine service.

The survey questions were designed based on critical components of interprofessional collaboration and communication identified by Garth et al including 1. Keeping the team in the loop (How often does the intern/resident update you with changes in the plan for your patient throughout the day?) 2. Asking for input from nonphysicians (On daily rounds, how often do you ask the nurse for input regarding your patient?) 3. Explaining rationale (How often do you explain to the nurse your rationale for ordering a particular medication, lab test, or imaging study?) 4. Joint problem solving (When you do speak up on rounds, how often do you feel that your concerns are heard?). ${ }^{2}$ The questions utilized in the surveys reflect themes present in published validated scales for collaboration. ${ }^{25}$

\section{The Co-Teaching Sessions}

All sessions took place in a conference room located on the medical unit. "Nurse" or "Doctor" place cards were alternately placed at the table to encourage nurses and residents to interact with each other. Sessions were attended by nurses, residents, nursing students, medical students, and senior physicians. Attendance was not required for these sessions. Each learner was given a packet containing the written audio-visual consent, verbal consent, and anonymous survey (Supplementary Appendix 3). The session was video-taped (HS) using a Partners HealthCare encrypted iPhone 8 (Apple, Inc, Cupertino, California).

At the end of the session, a Take-Away and a paper survey were given only to nurse and resident learners. The audio-video recording was uploaded to a Partners password protected Dropbox (Dropbox, Inc., San Francisco, California). Each co-teaching pair reviewed the video of the teaching session prior to uploading it to the Brigham and Women's Hospital (BWH) Video Education Library with their permission.

\section{Statistical Analyses}

Anonymous surveys were completed by nurse and resident learners for the post-co-teaching session data analysis. No surveys completed by nursing students, medical students, and/or senior physicians were included in the analysis. In order to assess pre- to post-co-teaching session changes in measures of interprofessional 
Table I Responses from Anonymous Nurse and Resident Learner Surveys after Each Nurse-Doctor Co-Teaching Session

\begin{tabular}{|c|c|c|c|c|c|c|c|c|c|c|c|c|}
\hline \multirow[b]{2}{*}{ Co-Teaching Session } & \multicolumn{3}{|c|}{ Overall Rating $^{\mathbf{a}}$} & \multicolumn{3}{|c|}{ Rated "Enjoyable"b } & \multicolumn{3}{|c|}{ Rated "Effective"c } & \multicolumn{3}{|c|}{ Wants Additional Sessions } \\
\hline & $\mathbf{n}$ & Mean & $\mathbf{s}$ & $\mathbf{n}$ & Mean & $\mathbf{s}$ & $\mathbf{n}$ & Mean & $\mathbf{s}$ & $\mathbf{n}$ & Mean & $\mathbf{s}$ \\
\hline A & 14 & 1.21 & 0.426 & 14 & 1.21 & 0.426 & 14 & 1.29 & 0.469 & 14 & 1.00 & 0.000 \\
\hline B & 10 & 1.10 & 0.316 & 10 & 1.10 & 0.316 & 10 & 1.20 & 0.632 & 10 & 1.10 & 0.316 \\
\hline C & 16 & 1.19 & 0.403 & 17 & 1.24 & 0.437 & 17 & 1.24 & 0.437 & 17 & 1.00 & 0.000 \\
\hline $\mathrm{D}$ & 11 & 1.00 & 0.000 & 11 & 1.18 & 0.405 & 11 & 1.18 & 0.405 & II & 1.00 & 0.000 \\
\hline E & 13 & 1.15 & 0.376 & 13 & 1.15 & 0.376 & 13 & 1.23 & 0.439 & 13 & 1.00 & 0.000 \\
\hline $\mathrm{F}$ & 12 & 1.33 & 0.492 & 12 & 1.42 & 0.515 & 12 & 1.33 & 0.495 & 12 & 1.00 & 0.000 \\
\hline G & 10 & 1.10 & 0.316 & 10 & 1.10 & 0.316 & 10 & 1.30 & 0.483 & 10 & 1.10 & 0.316 \\
\hline $\mathrm{H}$ & 14 & 1.43 & 0.514 & 14 & I.86* & 0.663 & 14 & I.7I & 0.607 & 14 & 1.07 & 0.267 \\
\hline I & 12 & 1.17 & 0.577 & 12 & 1.42 & 0.669 & 12 & 1.17 & 0.389 & 12 & 1.08 & 0.289 \\
\hline J & 8 & 1.13 & 0.354 & 8 & 1.88 & 0.641 & 8 & 1.63 & 0.518 & 8 & 1.00 & 0.000 \\
\hline
\end{tabular}

Notes: "'Overall, how would you rate today's session?” $(\mathrm{I}=$ Excellent $/ 4=$ Poor $)$. "How enjoyable was today's session?” $(\mathrm{I}=\mathrm{Very}$ enjoyable/5 = Not enjoyable at all). c"How effective were the methods of teaching in today's session?" ( $I=$ Very effective, $5=$ Not effective at all). "Would you like to have additional co-teaching sessions?" (Yes/No). *Statistically higher than all sessions except Session F, Session I and Session J at p-value $<0.05$ level.

collaboration and communication, data were analyzed using Z-tests for proportions. To assess differences in overall rating, enjoyability, and effectiveness across teaching sessions within each domain, survey data were analyzed using one-way analysis of variance (ANOVA) and Bonferroni multiple-comparison corrections (Table 1). Pearson's correlation analysis was used to explore associations between overall rating mean scores and the number of interactive teaching strategies used (Supplementary Appendix 4). The data were analyzed by the statistician (SP) using IBM SPSS Statistics for Windows, Version 27 (IBM Corp. Armonk, NY).

The study, with informed consent in the form of both written audio-visual consent and oral verbal consent, was approved by Partners HealthCare Institutional Review Board (the Institutional Review Board for Brigham and Women's Hospital) in June 2019.

\section{Results}

\section{Kickoff Dinner}

Ten participants (five nurses and five doctors) attended the "Kickoff Dinner". Six of ten participants filled out the post-session surveys. The one-question survey asked participants to provide an overall rating for the session with the choices of excellent, very good, good, fair, or poor. Five attendees rated the session as "excellent" and one attendee rated the session as "very good". Verbatim comments included: "was very helpful to see master teachers demonstrate teaching strategies" and "appreciated seeing demonstration of clinical co-teaching”.

\section{Co-Teaching Session Surveys}

Data from post-session surveys from all ten co-teaching sessions included 121 completed surveys out of 156 participants (77.6\%). Attendance at each session ranged from 13-19 participants with 8-17 surveys completed per session with an average of 12.1 surveys analyzed per session. Anonymous nurse and resident learner surveys after each co-teaching session evaluated the overall rating of the session, how enjoyable the session was, how effective the session was, and if the learner wanted additional co-teaching sessions (Table 1, Supplementary Appendix 3). Overall ratings for each session were evaluated on a Likert scale ranging from Excellent (1) to Poor (4). All Nurse-Doctor Co-Teaching sessions scored in the Excellent range between 1.00 to 1.43 on the Likert scale. No significant difference was noted for the overall rating among sessions.

Spontaneous nurse and resident responses to the postsession survey question "What did you like best?" are grouped according to the most frequent responses (Figure 2). The "Interactive" nature of the session was 


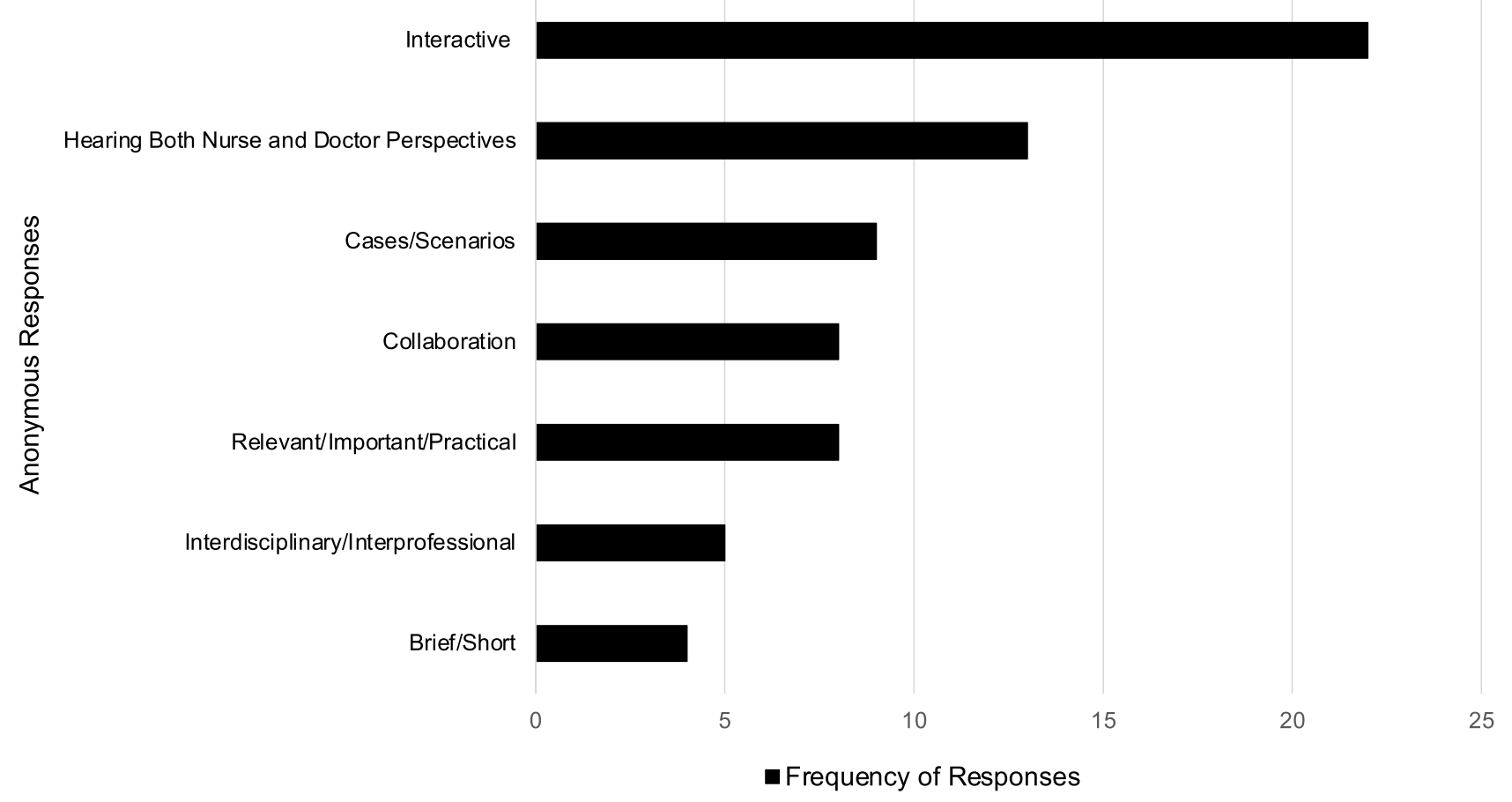

Figure 2 Top anonymous nurse and resident responses to the question "What did you like best about today's session?" Responses are from nurse and resident learner surveys collected after each Nurse-Doctor Co-Teaching session, where $\mathrm{n}=8$ to 17 surveys depending on the session. Categories of anonymous responses are listed on the $\mathrm{Y}$ axis. Frequency of responses ( $\mathrm{X}$ axis) represents the number of survey responses in each category totaled over the ten co-teaching sessions.

most frequently noted. The topics of each session and the types and number of interactive strategies used are shown in Table 2. Descriptions of the interactive teaching strategies used are shown in Table 3. In comparing the number of interactive strategies used and the mean score for enjoyable, there was a strong and significant correlation between the number of interactive strategies and degree of enjoyability (p-value=0.01) (Graph B, Supplementary Appendix 4). There was no correlation between the number of interactive strategies used and either the overall rating or effectiveness of the session (Graph A and C, Supplementary Appendix 4). Verbatim comments on what the nurse and resident participants liked best are displayed in Table 4.

\section{Pre- and Post-Intervention Surveys}

The number of pre-intervention surveys collected was 41 for nurses and 11 for residents. The number of post-intervention surveys collected was 41 for nurses and 12 for residents (Supplementary Appendices 1 and 2). Pre- and postintervention survey data were analyzed for significant differences. Nurses' comfort with asking residents about an order improved significantly in the post-intervention co-teaching period ( $\mathrm{N}=41$ Nurses) compared to the pre-intervention period ( $\mathrm{N}=41$ Nurses) by 14.6 percentage points going from
$85.4 \%$ to $100.0 \%$ (p-value $=0.01$ ). No significant difference was noted in residents' communication with nurses pre- and post-intervention from the anonymous surveys.

\section{Discussion}

The overall excellent ratings of the Nurse-Doctor CoTeaching series along with the learners' desire for additional sessions demonstrate that our pilot study achieved the primary goal of having nurses and doctors co-teach effectively together to a group of nurse and resident learners (Table 1). Our data suggest that these outcomes were due to two main aspects of our co-teaching sessions: 1 . The unique interprofessional model, with nurses and doctors as both teachers and learners. 2. Our structured format based on adult learning theory and resident preferences for learning, which included interactive teaching strategies. ${ }^{13-16}$

Malcolm Knowles noted that adults want to understand what and why they are learning and appreciate immediate applicability of the learning. ${ }^{13}$ We applied these concepts to our sessions by highlighting the importance of topic selection and learning objectives. Topics were chosen only after the Nurse and Doctor Co-Teaching pair agreed that the topic was both interesting and relevant to learners from both professions. The nurse-doctor pairs shared 
Table 2 Topics of the Ten Co-Teaching Sessions and the Number and Types of Interactive Teaching Strategies Used in Each Session

\begin{tabular}{|l|c|c|}
\hline Topic of Co-Teaching Session & $\begin{array}{c}\text { Number of Interactive Teaching } \\
\text { Strategies }\end{array}$ & $\begin{array}{c}\text { Types of Interactive Teaching Strategies Used in Co- } \\
\text { Teaching Session }\end{array}$ \\
\hline Arterial Blood Gases & I & Matching Columns \\
\hline Alcohol Withdrawal & 2 & Video with Scoring, Turn and Talk \\
\hline Hyponatremia & I & \begin{tabular}{c} 
Image Analysis \\
\hline Interruptions on Medical Units
\end{tabular} \\
\hline C. difficile Diagnosis \& Treatment & 3 & Polling, Hands-On Activity \\
\hline Opioid Withdrawal & 2 & Polling, Turn and Talk, Case Discussion \\
\hline Telemetry & 3 & Stand Up-Sit Down, Turn and Talk, Hands-On Activity \\
\hline $\begin{array}{l}\text { Catheter Associated Urinary Tract } \\
\text { Infections }\end{array}$ & 3 & Turn and Talk, Case Discussion, Polling, Design \\
\hline H. pylori Diagnosis and Treatment & 4 & Turn and Talk, Polling, Hands-On Activity \\
\hline Venous Thromboembolism & 3 & Turn and Talk, Polling, Design \\
\hline
\end{tabular}

Table 3 Description of the Interactive Teaching Strategies Used in Nurse-Doctor Co-Teaching Sessions

\begin{tabular}{|c|c|}
\hline $\begin{array}{l}\text { Interactive Teaching } \\
\text { Strategy }\end{array}$ & Description \\
\hline $\begin{array}{l}\text { Back-to-Back and Face-to- } \\
\text { Face }\end{array}$ & $\begin{array}{l}\text { In pairs, participants stand back-to-back, listening to a prompt or question. They have } 30 \text { seconds to think about their } \\
\text { response. Then, once the facilitator indicates the time is up, participants turn and face each other to discuss.* }\end{array}$ \\
\hline Case-Based Discussion & $\begin{array}{l}\text { Participants are introduced to a patient case and are asked to discuss the case at key moments, in pairs and/or as } \\
\text { a whole group. }\end{array}$ \\
\hline Design & $\begin{array}{l}\text { In teams, participants are challenged to design a solution to a clinical problem. For example, in one session they } \\
\text { designed an improved female urinary catheter.* In another, they were asked to design a discharge education sheet } \\
\text { for patients who had been diagnosed with a venous thromboembolism.*** }\end{array}$ \\
\hline Hands-On Activity & $\begin{array}{l}\text { Participants actively engage in "Hands-On" activities. For example, learners placed jellybeans on a diagram of the } \\
\text { torso in the correct locations of telemetry leads. }\end{array}$ \\
\hline Image Analysis & $\begin{array}{l}\text { Participants look at an image, often a mystery image. They write or discuss what they notice and wonder about the } \\
\text { image. }\end{array}$ \\
\hline Matching Columns & Participants are asked to match the item in Column A with an associated item in Column B. \\
\hline Polling & $\begin{array}{l}\text { Participants are polled for their responses to multiple choice questions using tools such as the Immediate Feedback } \\
\text { Assessment (IFAT) Cards.**** }\end{array}$ \\
\hline Scoring & $\begin{array}{l}\text { Participants score a scenario or case using an established rubric. For example, participants used the Clinical Institute } \\
\text { Withdrawal Assessment of Alcohol Scale, Revised (CIWA-Ar) to practice scoring a patient with alcohol withdrawal. }\end{array}$ \\
\hline Stand Up-Sit Down & $\begin{array}{l}\text { Participants share their thinking about a statement by standing up if they think the statement is true and staying seated } \\
\text { if they think it is false, or vice versa. }\end{array}$ \\
\hline Turn and Talk & Participants share their thinking about a question, problem, or scenario with their neighbor (s). \\
\hline
\end{tabular}

Notes: *Data from ElEducation.org. Expeditionary Learning: Classroom Protocols. Expeditionary Learning. Available from: https://curriculum.eleducation.org/sites/default/ files/curriculumtools_classroomprotocols_053017.pdf Back-To-Back and Face-To-Face, Page $8 .{ }^{32}$ **Supplementary Appendix 5. ****Supplementary Appendix 6.

****Immediate Feedback Assessment Technique, Epstein Educational Enterprises, Inc., Cincinnati, Ohio. 
Table 4 Verbatim Comments from Anonymous Nurse and Resident Learner Surveys on What the Learners Liked Best about the CoTeaching Session, Organized by Top Seven Categories of Response

\begin{tabular}{|c|c|c|}
\hline $\begin{array}{l}\text { "What Did You Like Best about } \\
\text { Today's Session?" }\end{array}$ & Anonymous Nurse Responses & Anonymous Resident Responses \\
\hline I. Interactive & $\begin{array}{l}\text { "Paired discussions" } \\
\text { "It was very engaging and interactive!" } \\
\text { "Being able to ask questions" }\end{array}$ & $\begin{array}{l}\text { "Interactive with clear takeaways" } \\
\text { "Seeing capsules + tubes, better appreciation for } \\
\text { logistics" } \\
\text { "Hands-on, visual experience" } \\
\text { "Scratch cards" } \\
\text { "Catheter design! Fun and interactive" }\end{array}$ \\
\hline $\begin{array}{l}\text { 2. Hearing Both Nurse and Doctor } \\
\text { Perspectives }\end{array}$ & $\begin{array}{l}\text { "Excellent co-presentation of both MD and RN } \\
\text { perspective" } \\
\text { "Great dual perspectives!" "Seeing both sides" }\end{array}$ & $\begin{array}{l}\text { "The fact that we got to hear from nurses too!" } \\
\text { "Hearing/learning from both perspectives" } \\
\text { "Learning about nursing driven protocol" } \\
\text { "Good to better understand each other's point of } \\
\text { views" }\end{array}$ \\
\hline 3. Cases/Scenarios & $\begin{array}{l}\text { "Activities/case studies" } \\
\text { "Scenarios" } \\
\text { "Case study" }\end{array}$ & $\begin{array}{l}\text { "Case-based questions" } \\
\text { "The quiz with review" } \\
\text { "Teaching on specific guidelines" } \\
\text { "Practical cases" } \\
\text { "Case was good, chatting with non-MDs" }\end{array}$ \\
\hline 4. Collaboration & $\begin{array}{l}\text { "Collaboration between RN and MDs = better } \\
\text { patient care!" "Very good teamwork" } \\
\text { "Collaboration with MD/nursing, very informative" }\end{array}$ & $\begin{array}{l}\text { "Always great to collaborate out of the high stress } \\
\text { environment on the floors" } \\
\text { "Led by both MD and RN" } \\
\text { "Teamwork emphasis, physician + nurse } \\
\text { collaboration" } \\
\text { "Shared with RN colleagues" }\end{array}$ \\
\hline $\begin{array}{l}\text { 5. Relevant, Important and/or } \\
\text { Practical }\end{array}$ & $\begin{array}{l}\text { "Real life examples" } \\
\text { "Can apply to practice" "Teaching was } \\
\text { straightforward and effective" } \\
\text { "Subject we deal with daily" } \\
\text { "Helpful topic, relevant" }\end{array}$ & $\begin{array}{l}\text { "Good mix of learning points for RNs and MDs" } \\
\text { "Very relevant topic and good use of different } \\
\text { teaching methods" } \\
\text { "Nurses point of view, very practical" } \\
\text { "Effective teaching methods" } \\
\text { "Practical info on treatment" }\end{array}$ \\
\hline 6. Interdisciplinary/Interprofessional & $\begin{array}{l}\text { "I love the collaboration between disciplines" } \\
\text { "The interdisciplinary discussions" }\end{array}$ & $\begin{array}{l}\text { "Interactive, interdisciplinary, relevant" } \\
\text { "Interdisciplinary interaction" }\end{array}$ \\
\hline 7. Brief/Short & $\begin{array}{l}\text { "Key points, not too long" } \\
\text { "Brief and informative" } \\
\text { "Excellent communication with great knowledge of } \\
\text { topic" }\end{array}$ & $\begin{array}{l}\text { "Brief, but very informative" } \\
\text { "Interactive, brief" } \\
\text { "Short, relevant" } \\
\text { "Clear explanations" }\end{array}$ \\
\hline
\end{tabular}

experiences and patient cases to find mutual learning objectives, which were taught using evidence-based content and interactive teaching strategies and reviewed in the form of a Take-Away. ${ }^{19,23,24}$ Recognition of the interprofessional relevance of educational content was demonstrated by learners' comments (Table 4).

Figure 2 provides insight into what the learners enjoyed "Best" about sessions, highlighting "Interactive" as the most frequent response (Figure 2, Table 4). Further analysis showed a significant correlation between the number of interactive strategies and the degree of enjoyability (Supplementary Appendix 5). Batalden has shown that faculty development to "experiment with a variety of educational methodologies including simulation, skills practice and games" can promote active learning for residents. ${ }^{16}$ In faculty development sessions provided by the coaching team, we encouraged the nurses and doctors to achieve Irby's definition of a dynamic teacher in the ambulatory setting, "Excellent clinical teachers were interested in teaching, were enthusiastic ... provided 
explanations and answered questions." ${ }^{26}$ We also adhered to Neher's important directive "time management is a critical function in clinical teaching" given that we had only thirty minutes for the co-teaching session. ${ }^{27}$ In addition, we recognized the importance of teaching "the same topic from multiple angles" and utilized modified teambased learning strategies for active engagement of the learners. ${ }^{19-22}$ We applied our knowledge of adult learning theory to select specific interactive strategies for each session that promoted discussion, creativity, and, in some cases, hands-on learning (Tables 2 and 3, Supplementary Appendices 5 and 6). ${ }^{13}$ The use of alternating "Nurse" and "Doctor" place cards on the tables encouraged nurses and residents to talk and work with each other. The interactive strategies combined with the orientation of learners in the room permitted "Hearing Both Nurse and Doctor Perspectives" which was also noted as a frequent response to what learners liked "Best" (Figure 2, Table 4).

The thoughtful topic selection and interactive teaching strategies were instrumental in creating a "positive learning climate" as outlined by Skeff. ${ }^{28}$ With guidance from the coaching team, the co-teachers were able to demonstrate "enthusiasm both for the content being taught and for teaching." ${ }^{28}$ Recognition of the enthusiastic collaborative efforts made by the Nurse-Doctor Co-Teaching pair were demonstrated by learners' comments in Table 4 .

\section{Limitations}

This was a pilot study at a single academic hospital to assess the effectiveness of an innovative Nurse-Doctor CoTeaching initiative and we recognize several important limitations to our study. First, while the pre- and postintervention surveys were based on published measures of interprofessional collaboration, we did not use a previously validated instrument to determine if changes occurred in the post- compared to pre-intervention period. ${ }^{2}$ Our decision to use our own survey tool was based on the fact that we wanted a brief, one-to-two-minute survey that would be convenient for nurses and residents to fill out on a paper form while on duty on the general medicine floor. In our expansion of this intervention, we will utilize one of the five validated instruments for nurse-physician collaboration which have been identified in a review by Dougherty and Larsen. ${ }^{25}$

While "collaboration" was noted as a theme in what learners liked best about the co-teaching sessions, we did not observe a significant increase in measures of nursedoctor collaboration, which is defined as a shared partnership. ${ }^{7}$ We observed an increase in nurses' comfort with asking residents about an order, however, we did not observe an increase in residents' communication with nurses about an order. It is important to note that residents in the pre-intervention group were different from those in the post-intervention group while the nurses were generally the same. This discrepancy is due to the underlying structure of the resident staffing at our institution and may have affected our survey outcomes. Additionally, interprofessional education research suggests that the "relationship building necessary for culture change occurs after long term commitment to interprofessional care" indicating we may need a longer study period in order to observe significant changes in interprofessional collaboration. ${ }^{1,29}$

\section{Challenges}

Major challenges included the time commitment required by the co-teachers as well as the coordination of practice sessions with the co-teachers and the coaching team. Previous studies with co-teaching in the medical setting have identified the same challenges. However, these studies also stress that the co-teaching method is "most effective when roles are defined and rehearsed" and that "Coteaching is a labor-intensive process. However, the gains appear significant". ${ }^{11,12}$ Similarly, in regards to active learning with residents, Sawatsky and colleagues note that "efforts to facilitate active learning in didactic sessions in residency are time consuming and require a lot of faculty time and effort". ${ }^{15}$

No compensation was provided to the nurses and doctors who volunteered to co-teach. We offered Continuing Education Units (CEU) for nurses who attended the Kickoff Dinner event (through the Alliance of Cardiovascular Professionals, Midlothian, Virginia). In the future, the opportunity to engage as a co-teacher may be enhanced if nurses and doctors are offered CEU or Continuing Medical Education (CME) credits for their significant time commitment. Given our positive results, we believe the implementation of a Nurse-Doctor CoTeaching intervention is worth the time and effort, but institutions should consider compensation for their coteachers.

\section{Next Steps}

One way to understand the process of co-teaching is to use focus groups, which are an effective qualitative data collection technique in medical education. ${ }^{30}$ Focus groups may offer insight into aspects of our structured co- 
teaching model and measures of nurse-doctor collaboration that may not be captured in a survey. We developed a focus group guide to explore the co-teaching experience from the perspective of both the co-teachers and the learners, but unfortunately these in-person groups were delayed due to the COVID-19 pandemic (Supplementary Appendix 7).

We have created a structured interprofessional coteaching format that can be adapted and readily reproduced. For example, the scope of interprofessional collaboration could be expanded to include pharmacists, physical therapists, dieticians, and social workers. ${ }^{31}$ The co-teaching sessions could take place in both the ambulatory and inpatient medical settings. Given the positive results of our pilot study, the leadership of nursing and medicine departments at our institution have recognized the value, the adaptability, and reproducibility of our Nurse-Doctor Co-Teaching intervention and have requested that our initiative be "scaled up" hospital-wide, expanding to the emergency room, surgical teams, and medical subspecialties.

\section{Conclusions}

We created a unique model of co-teaching with nurses and doctors as co-teachers and nurses and residents as colearners. The overall excellent ratings of our interactive sessions indicate that Nurse-Doctor Co-Teaching is a valued form of learning. Our structured format included learning objectives, evidence-based content, interactive teaching strategies, and a Take-Away of key content. Our model can be adapted to a variety of medical settings and expanded to include additional allied health professionals. We plan further studies to assess if Nurse-Doctor Co-Teaching improves measures of interprofessional collaboration.

\section{Approval}

The study was approved by the Partners HealthCare Institutional Review Board in June 2019.

\section{Acknowledgments}

The authors wish to thank all Nurse-Doctor Co-Teachers including Patricia Aylward, MSN, RN, CCRN-K, Brenda Bailey, RN, PCCN, Stephanie Bartelt, BSN, RN, PCCN, Ralph Blair, MD, Anuj Dalal, MD, Marliyatou Diallo, BSN, RN, Chandler Hicks, MSN, RN, Glen Kim, MD, $\mathrm{MPH}$, Bertha Lee, PhD, RN, Karen Lourence, MS, RN, PCCN, William Martin-Doyle, MD, MPH, Holli Murray, MSN, RN, PCCN, Lori Newman, MD, PhD, Christopher Roy, MD, David Rubins, MD, Agustina Saenz, MD, MPH,
Stephanie Simons, BSN, RN, Kellie St. Martin, MSN, RN, Tayana Vixama, BSN, RN, Bram Wispelwey, MD, MPH, MS. In addition, we wish to thank the Brigham and Women's Hospital Nursing Administration including Madelyn Pearson, DNP, RN, NEA-BC, Katie Fillipon, RN, MS, OCN, FNP, Christine Smith, MSN, RN, PCCN, Jillian Osborne, MSN, RN, Regina Hagono, MHA, and Emily Dehmer, MBA. We thank the Brigham and Women's Hospital General Medicine Unit Tower 14 Leadership including Robert Boxer, MD, PhD, Julieann Tamayo, and Jennifer Cartwright, MSN. We also thank the Brigham and Women's Hospital Internal Medicine Residents and the Brigham and Women's Hospital Internal Medicine Leadership including Joseph Loscalzo MD, PhD, Marshall Wolf, MD, and Joel Katz, MD.

We greatly appreciate the assistance of Angel Ayala, A. A, and Peter Linck, B.A, in editing and uploading the content of each co-teaching session to the Brigham and Women's Hospital's Video Education Library.

An abstract of this work was previously presented at the following meetings:

Brigham Education Institute Meeting, Brigham and Women's Hospital, November 2019; Brigham and Women's Hospital Department of Medicine Resident Research Day, June 2020; Society of Hospital Medicine Conference Virtual Poster and Virtual Oral Presentation, July 2020 .

\section{Funding}

There are no funding sources to disclose.

\section{Disclosure}

All authors declare that they have no conflicts of interest.

\section{References}

1. Dow A, Thibault G. Interprofessional education - a foundation for a new approach to health care. NEJM. 2017;377(9):803-805. doi:10.1056/NEJMp1705665

2. Garth M, Millet A, Shearer E, et al. Interprofessional Collaboration: a qualitative study of non-physician perspectives on residen competency. J Gen Intern Med. 2017;33:487-492. doi:10.1007/ s11606-017-4238-0

3. Ma C, Park SH, Shang J. Inter- and intra-disciplinary collaboration and patient safety outcomes in U.S. acute care hospital units: a cross-sectional study. Int J Nurs Stud. 2018;85:1-6. doi:10.1016/j. ijnurstu.2018.05.001

4. Walsh HA, Jolly Inouye AA, Goldman EF. Improving communication through resident-nurse shadowing. Hosp Pediatr. 2017;7(11):660-667. doi:10.1542/hpeds.2017-0001

5. Pinto MP, Kay ES, Wall MM, Choi CJ. Interprofessional collaboration improves the odds of educating patients about PrEP over time. J Gen Intern Med. 2020;35(5):1444-1451. doi:10.1007/s11606-019-05616-0 
6. O’Leary KJ, Wayne DB, Haviley C, Slade M, Lee J, Williams MV. Improving teamwork: impact of structured interdisciplinary rounds on a medical teaching unit. J Gen Intern Med. 2010;25(8):826-832. doi:10.1007/s11606-010-1345-6

7. Morley L, Cashell A. Collaboration in health care. J Med Imaging Radiat Sci. 2017;48(2):207-216. doi:10.1016/j.jmir.2017.02.071

8. Mckay KA, Narasimhan S. Bridging the gap between doctors and nurses. J Nurs Educ Pract. 2012;2:52-55.

9. Khowaja-Punjwani S, Smardo C, Hendricks MR, Lantos JD. Physician-nurse interactions in critical care. Pediatrics. 2017;140 (3):1-4. doi:10.1542/peds.2017-0670

10. Cook L, Friend M. Co-teaching: guidelines for creating effective practices. Focus Except Child. 1995;28:1-16.

11. Orlander JD, Gupta M, Fincke BG, Manning ME, Hershman W. Coteaching: a faculty development strategy. Med Educ. 2000;34 (4):257-265. doi:10.1046/j.1365-2923.2000.00494.x

12. Shi C, Rana J, Burgin S. Co-teaching: applications in medical education. Clin Teach. 2018;15(4):341-343. doi:10.1111/tct.12709

13. Knowles MS. Modern Practice of Adult Education: From Pedagogy to Andragogy. Englewood Cliffs, New Jersey: Prentice Hall Regents; 1980:13-62.

14. Sawatsky AP, Zickmund SL, Berlacher K, Lesky D, Granieri R. Understanding resident learning preferences within an internal medicine noon conference lecture series: a Qualitative Study. J Grad Med Educ. 2014;6(1):32-38. doi:10.4300/JGME-06-01-37.1

15. Sawatsky AP, Zickmund SL, Berlacher K, Lesky D, Granieri R. Understanding the challenges to facilitating active learning in resident conferences: a qualitative study of internal medicine faculty and resident perspectives. Med Educ Online. 2015;20(1):27289. doi:10.3402/meo.v20.27289

16. Batalden M, Warm EJ, Logio LS. Beyond a curricular design of convenience: replacing the noon conference with an academic half day in three internal medicine residency programs. Acad Med. 2013;88(5):644-651. doi:10.1097/ACM.0b013e31828b09f4

17. Caton JB, Pelletier SR, Shields HM. Asking what do residents' value most: a recent overview of internal medicine residents' learning preferences. Adv Med Educ Pract. 2018;9:509-518. doi:10.2147/ AMEP.S165717

18. Barnes LB, Christensen CR, Hansen AJ. Teaching and the Case Method. 3rd ed. Boston, MA, USA: Harvard Business School Press; 1994:79-80.

19. Shields HM. A Medical Teacher's Manual for Success: Five Simple Steps. Baltimore: The Johns Hopkins University Press; 2010:94-102, 111.
20. Haidet P, O’Malley KJ, Richards B. An initial experience with "team learning" in medical education. Acad Med. 2002;77:40-44. doi:10.1097/00001888-200201000-00009

21. Colbert J, Pelletier S, Xavier-Depina F, Shields H. A pilot study of team learning on in-patient rounds. Clin Teach. 2016;13(1):38-42. doi:10.1111/tct.12360

22. Inra JA, Pelletier S, Kumar NL, Barnes EL, Shields HM. An active learning curriculum improves fellows' knowledge and faculty teaching skills. Adv Med Educ Pract. 2017;8:359-364. doi:10.2147/ AMEP.S135538

23. Greenwald B. Teaching technical material. In: Christensen CR, Garvin DA, Sweet A, editors. Education for Judgment: The Artistry of Discussion Leadership. Boston: Harvard Business School Press; 1991:193-213.

24. Shields HM, Guss D, Somers SC, et al. A faculty development program to train tutors to be discussion leaders rather than facilitators. Acad Med. 2007;82(5):486-492. doi:10.1097/ ACM.0b013e31803eac9f

25. Dougherty MB, Larson E. A review of instruments measuring nurse-physician collaboration. J Nurs Adm. 2005;35(5):244-253. doi:10.1097/00005110-200505000-00008

26. Irby DM. Teaching and learning in ambulatory care settings: a thematic review of the literature. Acad Med. 1995;70 (10):898-931. doi:10.1097/00001888-199510000-00014

27. Neher JO, Stevens N. The one-minute preceptor: shaping the teaching conversation. Fam Med. 2003;35(6):391-393.

28. Skeff KM. Enhancing teaching effectiveness and vitality in the ambulatory setting. $J$ Gen Intern Med. 1988;3(1):S26-S33. doi:10.1007/BF02600249

29. Tomasik J, Fleming C. Lessons from the Field: Promising Interprofessional Collaboration Practices. USA: Robert Wood Johnson Foundation; 2015.

30. Stalmeijer RE, McNaughton N, Van Mook W. Using focus groups in medical education research: AMEE Guide No. 91. Med Teach. 2014;36(11):923-939. doi:10.3109/0142159X.2014.917165

31. Hogikyan E, Stojan J, Grob K, de Grave W, Daniel M. Co-teaching in an undergraduate clinical skills course: physicians and social behavioural scientists use a shared mental model to highlight complementary aspects of medical interviewing and physical exam skills. Med Ed Publish. 2019;8:62.

32. ElEducation.org. Expeditionary Learning: Classroom Protocols. Expeditionary Learning. Available from: https://curriculum.eleduca tion.org/sites/default/files/curriculumtools_classroomprotocols_ 053017.pdf. Accessed October 01, 2019.
Advances in Medical Education and Practice

\section{Publish your work in this journal}

Advances in Medical Education and Practice is an international, peerreviewed, open access journal that aims to present and publish research on Medical Education covering medical, dental, nursing and allied health care professional education. The journal covers undergraduate education, postgraduate training and continuing medical education including emerging trends and innovative models linking education, research, and health care services. The manuscript management system is completely online and includes a very quick and fair peer-review system. Visit http://www.dovepress.com/testimonials.php to read real quotes from published authors. 